\title{
Students' Motivations For Voluntary Remedial Learning In High School
}

Daniel Pelletier, University of Quebec in the Outaouais, Canada

Isabelle Green-Demers, University of Quebec in the Outaouais, Canada

Karine Lafleur, University of Quebec in the Outaouais, Canada

\begin{abstract}
Most high schools offer remedial learning sessions to their students; however, very little is known about the perception of these activities, especially with regards to the students' motivations. In order to gain insights into both topics, an exploratory study was conducted within a sample of 1388 high school students in the Province of Quebec (Canada). Participants were selected on the basis of their voluntary participation or non-participation in remedial learning sessions held at school. School motivation was measured with a questionnaire based on Deci and Ryan's SDT (Self Determination Theory); perceptions were gathered and measured with open-ended and multiple choice items. Quantitative results indicated that participants of remedial learning sessions were more strongly motivated towards school. No significant relationships were found between attendance and grades, with similar proportions of high, average and below average participating and non-participating students; however, among participants, girls outnumbered boys by 2:1. Two main categories emerged from qualitative analyses: remedial learning can be seen as: a) an instrumental support linked to the subject matter; or b) a relational support which fosters better learning.
\end{abstract}

Keywords: Remedial Learning; Motivation; Instrumental and Relational Support

\section{LITERATURE REVIEW}<smiles>[LiH]</smiles>

tudents often require special forms of help or support in order to get through high school. Such activities bear many different names: supplemental education or instruction, after-school tutoring or programs and remedial instruction or learning, to name just the most common ones. The term "remedial learning activities" for lack of a better term, will be used here. They encompass a wide array of programs, contingencies and designs which are made available to a heterogeneous group of participants (Glenn, 2008). This paper deals with the specific situation of students who are enrolled in main stream high schools with a regular curriculum. Many of them need extra help to get passing grades, better grades, or to prepare themselves for exams. A small number of students get help through private tutoring sessions, but most of them rely on what their school has to offer.

Such activities are distinct from what is known as "detention", i.e. mandatory periods of unsupervised school work imposed to students as a disciplinary measure, usually held after school hours. They are also different from specialized or adapted classes or learning activities, which are designed to help high-risk students or vulnerable populations, such as special students, chronic low-achievers, dropouts and even migrant students with language issues (Hock, Pulvers, Deshler and Schumaker, 2001; Mooney, Benner, Nelson, Lane and Beckers, 2008).

The remedial learning activities that will be studied here are subject matter specific and are voluntarily chosen by high school students according to their academic needs. A teacher or tutor is on hand to assist the participants either individually or collectively. More often than not they are held during school hours (for instance at lunch time) and occasionally after.

Attempts at reviewing the relevant documentation were fraught with difficulties for four reasons: 1) this type of remedial learning program is not covered by a generic term or specific keywords; 2) many of these programs 
are designed for beginners in college or university and they are aimed at filling voids in basic mathematic or linguistic abilities which should be mastered at the end of high school; 3) in high school, such programs are organized according to school specific constraints and resources which hinder the possibility of comparing them; 4) most of them are described in internal documents dealing almost exclusively with the logistics of the programs.

Notwithstanding the scarcity of documentation, a limited number of findings have emerged regarding high school based voluntary remedial learning. It seems that the effectiveness of these activities, in terms of better school achievement for the participants, is far from guaranteed, results being at the best inconclusive (Lavy and Schlosser, 2005). Three factors are cited as essential characteristics of successful programs: preparation of the tutors, length of the participant's commitment and specific goals (Baker, Rieg and Clendaniel, 2006).

In contrast, school motivation in adolescence has generated a lot of interest, research, and program or curriculum development efforts (Grubb, 2012) spanning a wide array of needs and theoretical models. Among these, the Deci and Ryan (1985) SDT model (Self Determination Theory) has been used extensively to assess, among others, the motivations of dropouts (Gillet, Berjot, Vallerand and Amoura, 2012; Vallerand, Fortier and Guay, 1997), delinquents (Norris, Snyder, Riem and Montaldi, 1996), regular students (Corpus, McClintic-Gilbert and Hayenga, 2009; Green-Demers, Legault, Pelletier and Pelletier, 2008; Robbins and Rogers, 2001), as well as high and low achievers (Guay, Ratelle and Chanal, 2008; Niemiec, and Ryan, 2009).

\section{PROBLEM STATEMENT, AIM, RESEARCH QUESTIONS}

Overall, SDT based research or intervention programs aimed at high school students have consistently replicated two findings: 1) school motivation linked to important personal goals or long term career objectives is associated to perseverance and achievement; 2) student school motivation is positively influenced by parent and teacher attitudes and behaviors which support autonomy, develop competence and foster personal affiliation with the student (Gottfried, Marcoulides, Gottfried and Oliver, 2009; Reeve and Jang, 2006). However, to the best of the authors' knowledge, no research has been published on the motivations of high school students who voluntarily take part in remedial learning activities. The aim here was to fill this void. Two research questions were investigated:

1. What are the motivation levels and academic status of students who did and did not take part in voluntary remedial activities?

2. What activity specific motivations were reported by participants and non-participants?

\section{METHOD}

\section{Participants}

Students enrolled in a large high school in a metropolitan area in the province of Quebec (Canada) voluntarily took part in this study $(\mathrm{N}=1388 ; 589 \mathrm{M}, 799 \mathrm{~F}$; mean age $=14,33$ yrs., S.D. $=1,55)$. All levels from junior to senior high were included; however, special education classes were not solicited in order to keep the sample homogeneous with regards to a normative school experience.

\section{Instruments}

Two instruments were used here: a school motivation scale and a combination of multiple choice and open ended questions dealing with the students' perceptions, attendance and motivations for voluntary remedial learning activities. The School Motivation Scale (Vallerand, Blais, Brière and Pelletier, 1989), is a 24 item 7 point Likert scale questionnaire which generates scores for each of the 6 types of motivation included in the Deci and Ryan SDT model: intrinsic motivation, extrinsic motivation by integrated, identified, introjected and external regulation and amotivation. An algorithm is used to combine these different scales into a single SDI (Self Determination Index) score which represents a composite of the strength and level of autonomy of motivation, higher scores indicating higher levels of motivation. The psychometric qualities of the instrument were deemed very well at the onset (Vallerand et al., 1989) and were further confirmed in latter studies. Multiple choice and open ended questions were used to gather information on the students' attendance, perceptions and the specific reasons why they attended the 
voluntary remedial learning activities or not. Academic achievement was assessed through self-reports expressed in percentage points.

\section{Procedure}

Both questionnaires were filled out during class towards the end of the fall semester in order to ensure sufficient exposure and enough opportunities to attend the remedial activities. Numerical data was coded in SPSS format while answers to open-ended questions were treated using a qualitative hierarchical classification procedure (Saldana, 2013).

\section{RESULTS}

Table 1 presents the means and standard deviations for age, motivation level and average overall grades for participants and non-participants. No significant differences were found for age; however, average grades were slightly higher for non-participants while school motivation scores were substantially higher for participants.

Table 1: Means, Standard Deviation (S.D.) and Significance of Age,

Motivation Level and Grade Differences According to Participation in Remedial Learning Activities

\begin{tabular}{|c|c|c|c|c|c|c|}
\hline \multirow[b]{2}{*}{ Age } & \multicolumn{2}{|c|}{$\begin{array}{c}\text { Participants } \\
(N=618)\end{array}$} & \multicolumn{2}{|c|}{$\begin{array}{c}\text { Non-Participants } \\
(\mathbf{N}=770)\end{array}$} & \multirow{2}{*}{$\frac{\mathbf{t}}{0,276}$} & \multirow{2}{*}{$\begin{array}{c}\text { Sig. } \\
\text { N.S. }\end{array}$} \\
\hline & 14,4344 & $(1,59567)$ & 14,4097 & $(1,50034)$ & & \\
\hline SDI score & 6,4271 & $(4,90514)$ & 4,4613 & $(5,93115)$ & 6,444 & $\mathrm{p}<.0001$ \\
\hline Grades (\%) & 75,2407 & $(8,80580)$ & 76,3792 & $(9,16169)$ & 2,199 & $p<.05$ \\
\hline
\end{tabular}

Table 2 presents the relative proportions of participants and non-participants according to gender and overall grade categories. They were created by applying cut-off points to the overall grade of each student in order to generate three equal groups: students with high, average and low overall grades. Results indicated the presence of a significant gender difference in the proportions of students participating in remedial activities, with girls outnumbering boys by 2:1. No significant differences in the relative proportions of participants and non-participants according to grade categories were observed. However, the highest proportions for all cross-tabulations were found for non-participants with higher grades $(39,6 \%)$ and participants with lower grades $(37,2 \%)$.

Table 2: Proportions of Participants and Non-Participants According to Gender and Overall Grade Categories (Lower, Average, Higher)

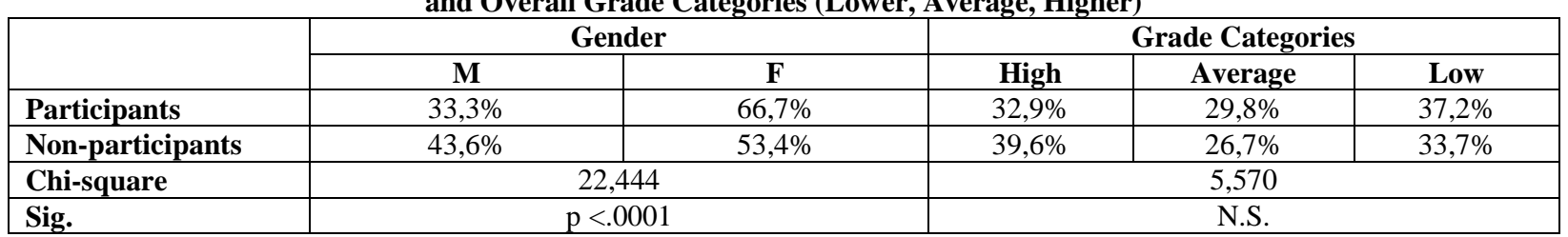

Open ended questions were used to gather qualitative information on the reasons and motives for attending and not attending voluntary remedial learning activities. A qualitative hierarchical classification procedure generated a conceptual framework which included to major nodes: instrumental and relational motives explaining both participation and non-participation in remedial activities (see Figure 1).

\section{DISCUSSION}

Simply in terms of attendance, voluntary remedial learning activities are an important support mechanism; more than $44 \%$ of enrolled students used this service during the fall semester. More importantly, the first research question dealt with the differential characteristics of participants and non-participants. As expected, school motivation scores were significantly higher for participants. One could hypothesize that because of the more immediate effects of failing courses for senior students, participation levels should be higher among older students, but such was not the case. Similarly, grades of non-participants should logically be higher than the grades of participants because of motivations linked to a sense of urgency. A slight albeit significant difference was observed, 
with a spread of less than two percentage points. Basically, the only substantial differences between participants and non-participants are on the one hand higher motivation scores and a significantly larger proportion of participating girls. Both results are consistent with previous research indicating that both motivated students and girls invest more time and energy in school related activities.

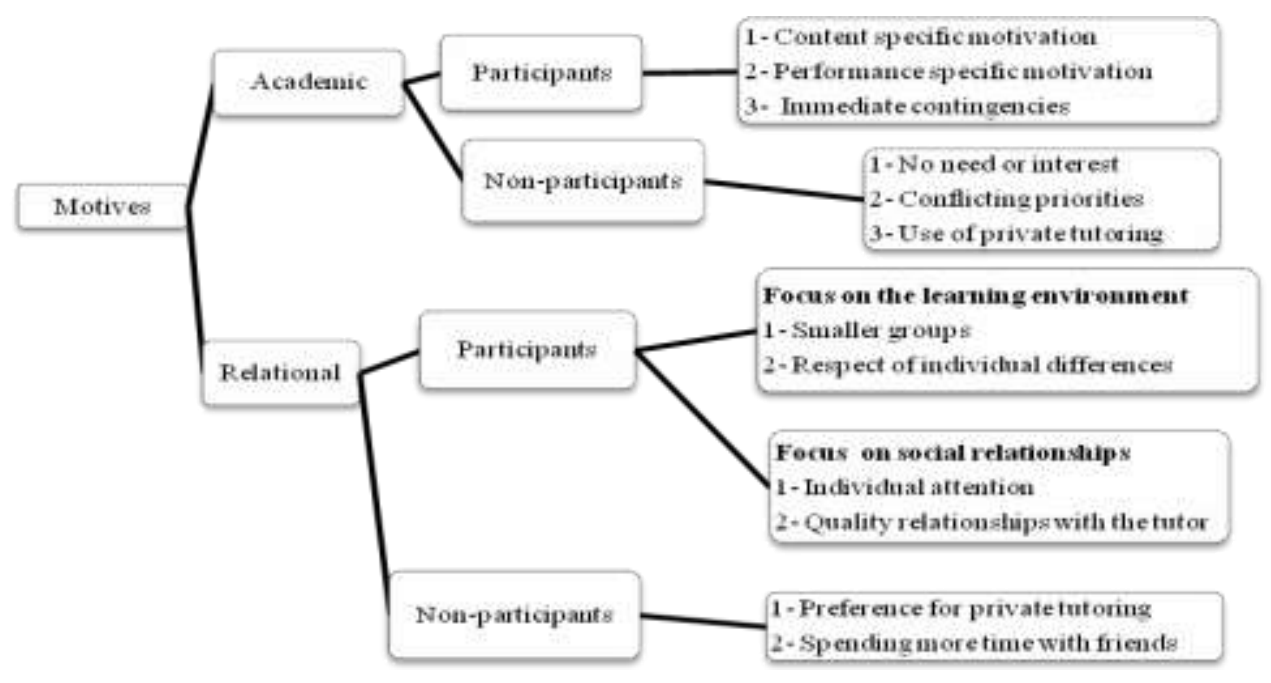

Figure 1: Hierarchical Classification of Motives Reported by Students According to their Participation in Voluntary Remedial Activities

Results also indicated that proportions of students with high, average and low achievement levels are not significantly different within the participating and non-participating groups. This was a puzzling result. After all, remedial learning is usually equated with lower grades and the need to improve them. However what is the added value of better grades for a low achiever who gets passing grades thanks to remedial learning as opposed to the situation of high achievers who deal with performance anxiety issues by using the same support mechanism? School motivation thus seems to trump the objective academic situation of students regarding their grades. Could it be that the relationship between school motivation and school performance is mediated by highly individualized expectations which were revealed by the qualitative analyses?

Two main categories of motives or reasons to participate or not in remedial learning activities were uncovered from the written comments and answers to the open-ended questions: relational motives and academic motives. Both needs can find some form of response within and outside of institutional remedial learning activities. For instance many students reported that they prefer getting help from their friends in a format which combines academic and social needs. Others see these activities as an academic lifeline saving them from failing courses while high achievers present them more or less like a springboard enabling them to get further ahead from their peers. All this raises the complex question of self-identified needs: wanting to take part in remedial activities does not automatically ensure an optimal student/intervention match. Some students clearly stated that academic motives were in the backdrop, their main concern being the possibility of having individualized positive interactions with selected teachers or tutors.

As it is so often the case in the field of education, the main findings of this research raise as many questions as those that have been partly answered. Most high schools are faced with important financial constraints which force them to make difficult choices between special education programs and support programs for regular students. Indeed, there is a fine line between the two, and voluntary remedial programs may act as a preventive measure protecting certain students from dropping out or getting failing grades. However, results reported here seem to indicate that students who voluntarily take part in remedial activities are more motivated in school and at least some of them use this opportunity to get higher than average grades, and not necessarily to avoid failing an exam or a 
course. At the same time, schools simply cannot multiply costly support measures tailored to every individual need. Here, three main types of motives were reported by participating students: 1) quality relationships with teachers in a low ratio setting; 2) the opportunity to study and learn in a more individualized environment; 3) specific subject matter problem-solving. This does not preclude the possibility that students who do not attend these remedial sessions could possibly benefit from them for any or all of the aforementioned reasons. The question is should students be encouraged to take part in these activities, if who have below average grades or students that are close to failing academically? On the other hand, is it a good idea to allow students who could simply have bouts of performance anxiety to benefit from costly services or opportunities? The answer probably rests in the intake procedures and duration of the interventions.

\section{CONCLUSION}

The exploratory nature of this research coupled with the use of a combined qualitative/quantitative approach must be taken into account before reaching any definitive conclusions. As stated earlier, remedial learning activities are not by any means standardized or readily comparable. Nonetheless, some useful insights can be derived from the results, especially with regards to the diversity of needs and motivations of students. A basic dropin one size fits all approach such as the one used here is easy to manage, the drawback being the absence of followup and limited guarantees regarding the length, the intensity and the appropriate nature of the support students get. To put it bluntly, if our only tool is a hammer, all our problems will soon look like nails! A revolving door approach through which students would receive a certain time allotment tailored to their needs and academic situation could probably improve the situation, especially if a more intensive intake measure bordering on special education is placed in continuity with voluntary activities at the more problematic end of the spectrum, and with lighter measures on the opposite end.

\section{AUTHOR INFORMATION}

Daniel Pelletier, University of Quebec in the Outaouais, Canada. E-mail: daniel.pelletier@uqo.ca (Corresponding author)

Isabelle Green-Demers, University of Quebec in the Outaouais, Canada. E-mail: isabelle.green-demers@uqo.ca

Karine Lafleur, University of Quebec in the Outaouais, Canada.

\section{REFERENCES}

1. Baker, J., Rieg, S. A., \& Clendaniel, T. (2006). An Investigation of an After School Math Tutoring Program: University Tutors + Elementary Students = A Successful Partnership. Education, 127, 287-293.

2. Corpus, J.M., McClintic-Gilbert, M., \& Hayenga, A. O. (2009).Within-year changes in children's intrinsic and extrinsic motivational orientations: Contextual predictors and academic outcomes. Contemporary Educational Psychology, 34, 154-166.

3. Deci, E. L., \& Ryan, R. M. (1985). Intrinsic motivation and self-determination in human behavior. New York, NY: Plenum.

4. Gillet, N., Berjot, S., Vallerand, R. J., \& Amoura, S. (2012): The Role of Autonomy Support and Motivation in the Prediction of Interest and Dropout Intentions in Sport and Education Settings. Basic and Applied Social Psychology, 34, 278-286.

5. Glenn, H. (2008) Remedial Education. EBSCO Research Starters. Washington: EBSCO Publishing Inc.

6. Gottfried, A. E., Marcoulides, G. A., Gottfried, A. W., \& Oliver, P. H. (2009). A latent curve model of parental motivational practices and developmental decline in math and science academic intrinsic motivation. Journal of Educational Psychology, 101, 729-739.

7. Green-Demers, I., Legault, L., Pelletier, D., \& Pelletier, L. G. (2008). Factorial Invariance of the Academic Amotivation Inventory (AAI) Across Gender and Grade in a Sample of Canadian High School Students. Educational \& Psychological Measurement, 68, 862-880.

8. Grubb, W. N. (2012). Rethinking Remedial Education and the Academic-Vocational Divide: Complementary Perspectives. Mind, Culture and Activity, 19, 22-25. 
9. Guay, F., Ratelle, C. F., \& Chanal, J. (2008). Optimal learning in optimal contexts: The role of selfdetermination in education. Canadian Psychology, 49, 233-240.

10. Hock, M. A., Pulvers, K. A., Deshler, D. D., \& Schumaker, J. B. (2001). The effects of an after-school tutoring program on the academic performance of at-risk students and students with L. D. Remedial and Special Education, 22, 172-186.

11. Lavy, V. \& Schlosser, A. (2005). Targeted Remedial Education for Underperforming Teenagers: Costs and Benefits. Journal of Labor Economics, 23, 839-874.

12. Mooney, P., Benner, G. J., Nelson, J. R., Lane, K. L., \& Beckers, G. (2008). Standard Protocol and Individualized Remedial Reading Interventions for Secondary Students With Emotional and Behavioral Disorders. Beyond Behavior, 17, 3-11.

13. Niemiec, C. P., \& Ryan, R. M. (2009). Autonomy, competence, and relatedness in the classroom: Applying self-determination theory to educational practice. Theory and Research in Education, 7, 133-144.

14. Norris, M.P., Snyder, D.K., Riem, K.E. \& Montaldi, D.F. (1996). Boot Camp Remedial Education Programs: Who Benefits? Journal of Correctional Education, 47, 140-146.

15. Reeve, J., \& Jang, H. (2006). What teachers say and do to support students' autonomy during a learning activity. Journal of Educational Psychology, 98, 209-218.

16. Saldana, J. (2013) The Coding Manual for Qualitative Researchers, Third Edition. Thousand Oaks: Sage.

17. Robbins, G.E. \& Rogers, D. E. (2001). Dogmatism and Study Time in High School Students: Better to be Wrong Than Long. Journal of Educational Research, 69, 120-123.

18. Vallerand, R.J., Blais, M.R., Brière, N.M. \& Pelletier, L.G. (1989). Construction et validation de l'échelle de motivation en éducation (Construction and validation of the school motivation scale). Revue Canadienne des Sciences du Comportement (Canadian Journal of Behavioral Science), 21, 323-349.

19. Vallerand, R. J., Fortier, M. S., \& Guay, F. (1997). Self-determination and persistence in a real-life setting: Toward a motivational model of high-school dropout. Journal of Personality and Social Psychology, 72, 1161-1176. 